\title{
Factors associated with mental distress among undergraduate students in northern Tanzania
}

Innocent B. Mboya ${ }^{1,2,3,4^{*}}$ (D), Beatrice John ${ }^{1}$, Eneck S. Kibopile ${ }^{1}$, Lisbeth Mhando ${ }^{3}$, Johnston George ${ }^{1}$ and James S. Ngocho ${ }^{2}$

\begin{abstract}
Background: Mental distress is a major public health problem which includes anxiety, depression and somatic symptoms such as sleeping problems, fatigue and headache. University students are consistently reported to have higher levels of mental distress compared to the general population. Although university students with mental distress have significantly impaired cognitive functioning, learning disabilities and poor academic performance, the burden of this problem in Tanzania is unknown. This study aimed to determine prevalence and factors associated with mental distress among undergraduate students in northern Tanzania.

Methods: A cross-sectional study was conducted among undergraduate students at Kilimanjaro Christian Medical University College from April-July 2018. Simple random sampling technique using probability proportional to size was used to sample students from their respective classes. Mental distress was screened using the self-reporting questionnaire (SRQ-20). Data was analyzed using Stata version 15.1. Frequencies and percentages were used to summarize categorical variables while mean and standard deviation for numeric variables. Multivariable logistic regression was used to determine factors associated with mental distress adjusted for potential confounders.

Results: A total of 402 undergraduate students participated in this study, 14\% screened positive for mental distress. Residing off-campus (OR=0.44,95\% Cl $0.20-0.96)$ and perceived availability of social support $(\mathrm{OR}=0.22,95 \% \mathrm{Cl} 0.11$ $0.45)$ reduced the odds of mental distress while students with family history of mental distress $(\mathrm{OR}=2.60,95 \% \mathrm{Cl}$ 1.04-6.57) and those with decreased grades than anticipated $(\mathrm{OR}=3.61,95 \% \mathrm{Cl} 1.91-6.83)$ had higher likelihood of mental distress.

Conclusion: One in every ten students screened was positive for mental distress. Those who reported a family history of mental illness and lower grades than anticipated had higher response of mental distress. To relieve students from stress and frustrations related to studies and their lives in general, this study recommends awareness creation, counselling to help those with mental health issues, establishment of student drop-in centers for such services and promotion of social and recreational activities at the college.
\end{abstract}

Keywords: Mental distress, Mental health, Mental illness, Undergraduate students, Tanzania

\footnotetext{
*Correspondence: ib.mboya@gmail.com

'Institute of Public Health, Community Health Department, Kilimanjaro Christian Medical University College (KCMUCo), P. O. Box 2240, Moshi,

Tanzania

${ }^{2}$ Institute of Public Health, Department of Epidemiology and Biostatistics,

Kilimanjaro Christian Medical University College (KCMUCo), P. O. Box 2240,

Moshi, Tanzania

Full list of author information is available at the end of the article
}

(c) The Author(s). 2020 Open Access This article is distributed under the terms of the Creative Commons Attribution 4.0 International License (http://creativecommons.org/licenses/by/4.0/), which permits unrestricted use, distribution, and reproduction in any medium, provided you give appropriate credit to the original author(s) and the source, provide a link to the Creative Commons license, and indicate if changes were made. The Creative Commons Public Domain Dedication waiver (http://creativecommons.org/publicdomain/zero/1.0/) applies to the data made available in this article, unless otherwise stated. 


\section{Background}

Mental distress is a major public health problem that affect society as a whole and it includes mental problems such as anxiety, depression and somatic symptoms for example sleeping problems, fatigue, headache and back ache $[1,2]$. University students are consistently reported to have higher levels of mental distress compared to the general population [1-4]. For instance, significantly higher levels of mental distress were reported among Australian medical students as compared to the general population $[4,5]$.

Higher prevalence of mental distress among university students have also been reported in Asian and subSaharan Africa countries [3, 6-10]. The highest observed proportion was $71.9 \%$ among medical students in Jizan University, Kingdom of Saudi Arabia [11] which is almost similar to that reported in Tanzania (70\%) among non-medical students in Dar Es Salaam [12]. Mental health problems such as mental distress are not well documented in Tanzania. The proportions of mental distress among undergraduate students in medical institutions in other studies are high, which may also be true among students in Tanzania. Data from this population is crucial in promoting health and well-being in the student population [13].

University students with higher proportion of mental distress are likely to experience negative consequences such as significant impaired cognitive functioning, learning disabilities, poor academic performance, substance abuse (e.g. cigarette/tobacco smoking, alcohol use and khat chewing) which are associated with risk behaviors $[8,14]$, higher risk of depression as well as anxiety disorders [8]. This indicates that, mental distress increases the risk of other mental health problems.

Mental distress among university students has been associated with several factors such as sex (i.e. female students reporting higher levels compared to males), lack of interest towards the field of study, not having close friends, never attending religious programs, conflict with friends, financial problems, family history of mental illness, use of drugs such as khat, lack of break or vacation, limited social support, examinations, very tight schedules and lack of extracurricular activities around the campus $[1,5,10,11]$.

Tanzania, as other low- and middle-income countries faces many challenges in meeting mental health needs, being among one of the least prioritized areas. These include inadequate number of trained personnel in mental health, misplacement of human resource for mental health, lack of specific treatment, problematic insurance coverage for mental disorders, and stigma attached to mental health problems [15]. Due to these challenges, mental health problems may be intensified especially in key populations such as university students. This study aimed at determining prevalence and factors associated with mental distress among undergraduate students in northern Tanzania.

\section{Methods \\ Study design and setting}

This cross-sectional study was conducted from AprilJuly 2018 at Kilimanjaro Christian Medical University College (KCMUCo). KCMUCo is among the four universities in Moshi Municipality, northern Tanzania and is the only university in the region offering medical education and other allied health programs. Programs offered in this higher learning institution includes Diploma and Bachelor's in health laboratories, Bachelor in Nursing, Diploma in Occupation Therapy, Diploma and Bachelor in Physiotherapy, Diploma and Bachelor in Prosthetics and Orthotics, Doctor of Medicine, Bachelor in Optometry and Diploma in HIV and AIDS care. The college had a total of 1100 undergraduate students in the year 2018.

\section{Study population and sample size}

The study population was undergraduate students at KCMUCo who were in class during the data collection period and provided their informed consent. A single proportion formula was used for sample size calculation using a standard normal value of 1.96 at $95 \%$ confidence interval, $5 \%$ margin of error and an estimated prevalence of mental distress among undergraduate students of the University of Gondar University in Ethiopia (40.9\%) [1]. Adding $10 \%$ of non-response, the minimum required sample size was estimated to be 410 participants. Simple random sampling technique using probability proportional to size was used to sample students from their respective classes.

\section{Study variables}

The dependent variable was mental distress which was measured using a self-reporting questionnaire (SRQ-20). The SRQ-20 is a standardized questionnaire having 20 item questions, originally developed by World Health Organization (WHO) to indicate mental distress $[1,16]$. The SRQ-20 has been validated in low- and middleincome countries and found to be highly sensitive and specific [16-21]. The tool has also been used among university students in several studies in African settings $[1,8,9]$. Students in this study were asked if they experienced the SRQ-20 symptoms within 1 month preceding the survey. Those with a score of 8 or more were considered having mental distress $[1,9]$. Independent variables included; background characteristics such as age in years, sex, year of study, area of residence (on-campus and off-campus) and smoking status (ever smoking tobacco, marijuana or both). Family history of mental 
illness, history of alcohol use, lack of break or vacation, increased class work load, decreased grades than anticipated and missing too many classes were measured as binary (yes and no). Perceived social support was measured using a 12 items social support questionnaire (SSQ) with responses ranging from strongly agree-1 to strongly disagree-5 [22]. After performing principal component analysis (PCA), 11 out of 12 statements predicted the first component. The remaining statements were added and divided by 11 to compute social support variable. The values obtained ranged from 1 to 4.9. Participants with 1 to 2 values were categorized as having social support. Statements and results used to generate social support variable are provided in the Additional file 1.

\section{Data collection}

Students were given a questionnaire to fill-out (see Additional file 2). The questionnaire was in English, an official language at higher learning institutions in Tanzania. Data collection was performed by three trained medicine students at KCMUCo. Data collectors visited undergraduate students in their respective classes and clearly explained the purpose of the study. Once all questions or concerns related to the study were addressed, students were sampled proportional to the size of each class and were administered informed consent. Following a written consent, students were given a questionnaire to complete which took a maximum of $25 \mathrm{~min}$. The trained student data-collectors did not also complete a survey. Finally, all the completed questionnaires were collected and reviewed for completeness.

\section{Statistical analysis}

Data was entered and cleaned using Statistical Package for Social Science (SPSS) (SPSS Inc., Chicago, IL) version 21 and analyzed using STATA ${ }^{\bullet}$ software (Stata Corp LP) version 15.1. Frequency and percentages were used to describe prevalence of mental distress. Means and standard deviations were used to summarize numeric variables. Cronbach's alpha was used to assess reliability of the 12 statements used to measure availability of social support that provided a scale of $88.6 \%$. Principal component analysis was used to extract a total of 11 out of 12 statements that measured availability of social support in this study. From these, social support was computed as a binary variable.

Odds ratios (ORs) with 95\% confidence intervals (CIs) for factors associated with mental distress were estimated using a multivariable logistic regression model. Stepwise logistic regression was used to select variables to be included in the multivariable model at $10 \%$ significance level. Likelihood ratio test was used to compare a model with and without interaction providing evidence for a later model. A $p$-value of less than $5 \%$ was considered statistically significant.

\section{Results \\ Background characteristics of study participants}

The study enrolled a total of 402 undergraduate students at KCMUCo. The mean age of study participants was 24 years and standard deviation of 2.4 years. Half of participants (50.5\%) were pursuing medicine program while nursing students accounted for $22 \%$ of the sample. Of all respondents, $92.8 \%$ received government funding through higher education student loans board scheme. The proportion of students who reported family history of mental illness was $7.5 \%$ while $53.2 \%$ reported availability of social support system when needed (Table 1).

\section{Reported academic challenges}

The most common academic challenges reported among study participants were: increased class workload (33.1\%), lack of vacation or break (37.3\%) and decreased grade than anticipated (21.1\%) (Table 2).

\section{Proportion of students screened positive for mental distress}

The distribution of questions used to measure mental distress are shown in Table 3. Among 402 students who participated in this study, 56 (13.9\%) screened positive for mental distress.

\section{Factors associated with mental distress}

Factors found to be significantly associated with mental distress in the crude analysis were year of study, family history of mental illness, availability of social support, increased class workload, deceased grade than anticipated, missing too many classes and lack of vacation (Table 4).

In the multivariable logistic regression analysis, stepwise regression was fit including variables that were statistically significant in the crude analysis. Age and sex were considered as potential confounders though results from the crude analysis did not show a significant association with mental distress. Likelihood ratio test was used to assess the effect of including or excluding age and sex in the final model which showed no statistically significant effect $(p>0.05)$ of including them in the final model. Therefore, the final multivariable model indicated that, student's area of residence, family history of mental illness, perceived availability of social support and decreased grade than anticipated were the factors significantly $(p<0.05)$ associated with mental distress in this population (Table 4). Residing off-campus (OR = $0.44,95 \% \mathrm{CI} 0.20-0.96)$ and perceived availability of social support $(\mathrm{OR}=0.22,95 \% \mathrm{CI} 0.11-0.45)$ reduced the odds of mental distress while higher odds of mental distress were found among students with family history of 
Table 1 Background characteristics of study participants $(N=402)$

\begin{tabular}{ll}
\hline Variable & $n$ \\
\hline Age (years) & \\
Mean (SD) & 24 \\
$20-24$ & 281 \\
$25+$ & 121 \\
Sex & \\
Male & 243 \\
Female & 159
\end{tabular}

Place of residence

On-campus

Off-campus

Year of study

Second year

Third year

175

Fourth and fifth years

Program of study

Doctor of medicine

Nursing

Others $^{a}$

Source of funding

$$
\begin{aligned}
& \text { Family/personal } \\
& \text { HESLB }
\end{aligned}
$$

Sponsor

Marital status

Single

Married/ Cohabiting

Have pocket money

$\begin{array}{ll}\text { No } & 115 \\ \text { Yes } & 287\end{array}$

Reported family history of mental illness

$\begin{array}{ll}\text { No } & 372 \\ \text { Yes } & 30\end{array}$

Ever drank alcohol

$\begin{array}{ll}\text { No } & 290 \\ \text { Yes } & 112\end{array}$

Ever smoked tobacco or marijuana

$\begin{array}{ll}\text { No } & 359 \\ \text { Yes } & 43\end{array}$

Social support available

No

Yes

214

${ }^{a}$ Other programs of study included; laboratory sciences (14.2\%), physiotherapy (7.0\%), prosthetics and orthotics $(3.7 \%)$ and optometry $(2.7 \%)$. HESLB, Higher Education Students' Loans Board
Table 2 Reported academic challenges

\begin{tabular}{lcc}
\hline Variable & Frequency & Percentage \\
\hline Increase class work load & & 66.9 \\
No & 269 & 33.1 \\
Yes & 133 & \\
Decreased grade than anticipated & 78.9 \\
No & 317 & 21.1 \\
Yes & 85 & \\
Missed too many classes & & 90.0 \\
No & 362 & 10.0 \\
Yes & 40 & \\
Serious argument with instructors & 92.0 \\
No & 370 & 8.0 \\
Yes & 32 & \\
Lack of vacation/ break & & 62.7 \\
No & 252 & 37.3 \\
Yes & 150 &
\end{tabular}

\begin{tabular}{|c|c|c|}
\hline Symptoms of mental distress ${ }^{a}$ & Frequency $^{\mathrm{b}}$ & Percentage $^{\mathrm{b}}$ \\
\hline Often have headache & 106 & 26.4 \\
\hline Poor appetite & 61 & 15.2 \\
\hline Lack of sleep & 64 & 15.9 \\
\hline Easily frightened & 61 & 15.2 \\
\hline Uncontrollable hand shaking & 37 & 9.2 \\
\hline Feeling nervous & 67 & 16.7 \\
\hline Poor digestion & 49 & 12.2 \\
\hline Trouble on thinking & 40 & 10 \\
\hline Feeling unhappy & 69 & 17.2 \\
\hline Crying more than usual & 23 & 5.7 \\
\hline Difficult to enjoy daily activities & 57 & 14.2 \\
\hline Daily work suffering & 41 & 10.2 \\
\hline Unable to play a useful part in life & 43 & 10.7 \\
\hline Lost interest in things & 92 & 22.9 \\
\hline Feeling of worthlessness & 38 & 9.5 \\
\hline Thought of ending life & 43 & 10.7 \\
\hline Feeling tired all the time & 50 & 12.4 \\
\hline Uncomfortable feeling in the stomach & 71 & 17.7 \\
\hline Difficult to make decisions & 59 & 14.7 \\
\hline Easily tired & 66 & 16.4 \\
\hline \multicolumn{3}{|l|}{ Mental distress } \\
\hline Yes & 56 & 13.9 \\
\hline No & 346 & 86.1 \\
\hline
\end{tabular}

Table 3 Symptoms of mental distress ( $N=402)$

${ }^{\mathrm{a} S y m p t o m s ~ b a s e d ~ o n ~ s e l f-r e p o r t i n g ~ q u e s t i o n n a i r e ~(S R Q-20) ~ o r i g i n a l l y ~}$ developed by WHO. ${ }^{\mathrm{b}}$ Frequency and percentage among those who answered "Yes" 
Table 4 Crude odds ratio for factors associated with mental distress

\begin{tabular}{|c|c|c|c|c|c|c|}
\hline Characteristics & $\mathrm{n}$ & Have mental distress (\%) & $\operatorname{COR}^{\mathrm{a}}(95 \% \mathrm{Cl})$ & $p$-value & $\mathrm{AOR}^{\mathrm{b}}(95 \% \mathrm{Cl})$ & $p$-value \\
\hline \multicolumn{7}{|l|}{ Age (years) } \\
\hline $20-24$ & 281 & $40(14.2)$ & 1 & & & \\
\hline $25+$ & 121 & $16(13.2)$ & $0.92(0.49-1.71)$ & 0.79 & - & \\
\hline \multicolumn{7}{|l|}{ Sex } \\
\hline Male & 243 & $32(13.2)$ & 1 & & & \\
\hline Female & 159 & $24(15.1)$ & $1.17(0.66-2.08)$ & 0.59 & - & \\
\hline \multicolumn{7}{|l|}{ Residence } \\
\hline On-campus & 60 & $13(21.7)$ & 1 & & 1 & \\
\hline Off-campus & 342 & $43(12.6)$ & $0.52(0.26-1.04)$ & 0.06 & $0.44(0.20-0.96)$ & 0.04 \\
\hline \multicolumn{7}{|l|}{ Year of study } \\
\hline Second year & 127 & $24(18.9)$ & 1 & & & \\
\hline Third year & 175 & $16(9.1)$ & $0.43(0.22-0.85)$ & 0.02 & - & \\
\hline Fourth and fifth years & 100 & $16(16.0)$ & $0.82(0.41-1.64)$ & 0.57 & - & \\
\hline \multicolumn{7}{|c|}{ Reported family history of mental illness } \\
\hline No & 372 & $46(12.4)$ & 1 & & 1 & \\
\hline Yes & 30 & $10(33.3)$ & $3.54(1.56-8.04)$ & 0.002 & $2.60(1.04-6.57)$ & 0.04 \\
\hline \multicolumn{7}{|l|}{ Ever drank alcohol } \\
\hline No & 290 & $40(13.8)$ & 1 & & & \\
\hline Yes & 112 & $16(14.3)$ & $1.04(0.56-1.95)$ & 0.90 & - & \\
\hline \multicolumn{7}{|c|}{ Ever smoked tobacco or marijuana } \\
\hline No & 358 & $46(12.8)$ & 1 & & & \\
\hline Yes & 43 & $10(23.3)$ & $2.06(0.95-4.46)$ & 0.07 & $2.37(1.00-5.59)$ & 0.05 \\
\hline \multicolumn{7}{|l|}{ Social support available } \\
\hline No & 188 & $43(22.9)$ & 1 & & 1 & \\
\hline Yes & 214 & $13(6.1)$ & $0.22(0.11-0.42)$ & $<0.001$ & $0.22(0.11-0.45)$ & $<0.001$ \\
\hline \multicolumn{7}{|l|}{ Increase class work load } \\
\hline No & 269 & $28(10.4)$ & 1 & & & \\
\hline Yes & 133 & $28(21.1)$ & $2.30(1.29-4.07)$ & 0.004 & - & \\
\hline \multicolumn{7}{|c|}{ Decreased grade than anticipated } \\
\hline No & 317 & $30(9.5)$ & 1 & & 1 & \\
\hline Yes & 85 & $26(30.6)$ & $4.22(2.32-7.65)$ & $<0.001$ & $3.61(1.91-6.83)$ & $<0.001$ \\
\hline \multicolumn{7}{|l|}{ Missed too many classes } \\
\hline No & 362 & $45(12.4)$ & 1 & & & \\
\hline Yes & 40 & $11(27.5)$ & $2.67(1.25-5.72)$ & 0.01 & - & \\
\hline \multicolumn{7}{|c|}{ Serious argument with instructors } \\
\hline No & 370 & $48(13.0)$ & 1 & & & \\
\hline Yes & 32 & $8(25.0)$ & $2.24(0.95-5.26)$ & 0.07 & - & \\
\hline \multicolumn{7}{|l|}{ Lack of vacation/ break } \\
\hline No & 252 & $26(10.3)$ & 1 & & & \\
\hline Yes & 150 & $30(20.0)$ & $2.17(1.23-3.84)$ & 0.008 & - & \\
\hline
\end{tabular}

${ }^{a} \mathrm{COR}$ - Crude odds ratio. ${ }^{\mathbf{b}} \mathrm{AOR}$ Adjusted odds ratio - adjusted for area of residence, family history of mental illness, availability of social support, decreased grade than anticipated, alcohol use and smoking status 
mental distress $(\mathrm{OR}=2.60,95 \% \mathrm{CI} 1.04-6.57)$ and those with decreased grades than anticipated $(\mathrm{OR}=3.61$, 95\% CI 1.91-6.83).

\section{Discussion}

This study aimed to determine prevalence and factors associated with mental distress among undergraduate students in northern Tanzania. About 14\% of undergraduate students in this population screened positive for mental distress. Area of residence, family history of mental illness, availability of social support and decreased grade than anticipated were the factors found to be significantly associated with mental distress.

Prevalence of mental distress among undergraduate students in this study is similar to that reported in France (12.6\%) [23]. However, our estimate is lower than those reported in Ethiopia (29.2-41\%) [1, 2, 9] and Somalia (19.8\%) [8]. Significant differences observed in Ethiopia can be explained by the scoring of the items where in this study the scores ranged from 1-strongly agree to 5-strongly disagree as compared to [1] whose scores ranged from 1-very strongly disagree to 7-very strongly agree. The study also had a larger sample size compared to the current study. Moreover, other studies included first year students who are likely to face difficulties in adapting to the university environment but were not available to participate in this study. James et al., [3] assessed perceived medical students stress but used scores instead of a binary categorical variable that estimates prevalence/proportion as done in this study. A qualitative study in UK also reported that many of the students were suffering from mental distress whereby stigma attached to this issue intensifies the problem [13].

Lower odds of mental distress were observed among students who were residing off-campus. It is possible that, those who were residing on-campus were probably spending more time studying compared to those staying off-campus. While the later could also be using college premises to study, they are forced to leave earlier due to safety issues [9]. In Australia, accommodation circumstances (such as living in rental houses as opposed to family or own homes) and longer travel times increased the likelihood of having mental distress [5]. Only $15 \%$ of students in this study were residing on-campus. College accommodation should therefore be promoted as one of the potential strategies to support students manage stress.

Availability of social support among undergraduate students in this study reduced the odds of mental distress as also reported in Ethiopia [1]. This implies that, having available support from both friends and family members reduces stress associated with studies and adjusting to the college environment. Not having a satisfying relationship with the family increased the risk of mental distress in Somalia and Ethiopia [2, 8]. There is a need to encourage university students to establish healthy relationships with both their families, friends and fellow students in order to reduce the burden of this problem. Student support services at the college should also be strengthened such as using peer counselors who will play role in addressing and eventually reducing mental health issues among undergraduate students.

Furthermore, similar to a study in Ethiopia [1], family history of mental illness significantly increased the odds of mental distress in this study. This may be explained by genetic predisposition in addition to challenges associated with caring for a mentally ill family member [1, 24]. Students with family history of mental illness may benefit from counselling services if they are made available both at the college and the surrounding community environment.

The amount of stress is likely to increase among university students because of a high parental expectation, very tight academic program and during examinations period which also increases after receiving unexpectedly low scores $[3,10,11]$. In this study, students experiencing decreased grades than anticipated had higher odds of mental distress. This could imply that, university students are likely to experience depression, anxiety, frustration and troubles sleeping among other mental health issues due to stress associated with their academic lives $[14,23,25]$.

The current study is the first to determine the burden of mental distress among undergraduate university students in Tanzania. This study may have been prone to information bias whereby students might have misreported information related to different symptoms of mental distress as well as engagement in risk behaviors such as alcohol and drug use.

\section{Conclusions}

Prevalence of mental distress was found to be $14 \%$. Factors associated with mental distress among undergraduate students in this study are area of residence, availability of social support, family history of mental illness and decreased grades than anticipated. This study recommends awareness creation as well as counselling to help students with mental health issues such as mental distress. Universities and colleges should consider establishing student drop-in centers that will provide counselling services to students experiencing different mental health issues. Social and recreational activities at the college can play a significant role in relieving students from stress and frustrations related to studies and their lives in general. 


\section{Supplementary information}

Supplementary information accompanies this paper at https://doi.org/10. 1186/s12888-020-2448-1

Additional file 1: Table S1. Perceived availability of social support.

Additional file 2. Questionnaire used to assess prevalence and factors associated with mental distress among undergraduate students at KCMUCo.

\section{Abbreviations}

KCMUCo: Kilimanjaro Christian Medical University College; OR: Odds Ratio; SRQ-20: Self-Reporting Questionnaire-20

\section{Acknowledgements}

This study was carried out as part of Doctor of Medicine Training by three undergraduate students (including the third author) at Kilimanjaro Christian Medical University College. We would like to acknowledge Furaha E. Kasyupa and Esther Andrew for actively participating in data collection. Special thanks to all undergraduate students who consented and took part in this study.

\section{Authors' contributions}

IBM, ESK and JG designed the study, ESK participated in data collection, IBM, BJ and ESK analyzed and interpreted the data, IBM drafted the manuscript, LM and JNG critically reviewed the manuscript. All authors reviewed and approved the final manuscript.

\section{Funding}

The authors received no specific funding for this work.

\section{Availability of data and materials}

The datasets used and/or analyzed during the current study are available from the corresponding author on reasonable request.

\section{Ethics approval and consent to participate}

The ethical approval number 2418 was obtained from Kilimanjaro Christian Medical University College Research Ethics and Review Committee (KCMUCRERC). Written informed consent was sought from all study participants prior to the interviews. Confidentiality and privacy were maintained by using unique identification numbers instead of names.

\section{Consent for publication}

Not applicable.

\section{Competing interests}

The authors declare that they have no competing interests.

\section{Author details}

${ }^{1}$ Institute of Public Health, Community Health Department, Kilimanjaro Christian Medical University College (KCMUCo), P. O. Box 2240, Moshi, Tanzania. ${ }^{2}$ Institute of Public Health, Department of Epidemiology and Biostatistics, Kilimanjaro Christian Medical University College (KCMUCO), P. O. Box 2240, Moshi, Tanzania. ${ }^{3}$ Institute of Public Health, Department of Behavioral and Social Sciences, Kilimanjaro Christian Medical University College (KCMUCo), P. O. Box 2240, Moshi, Tanzania. ${ }^{4}$ School of Mathematics, Statistics \& Computer Science, University of KwaZulu-Natal, Pietermaritzburg, Private Bag X01, Scottsville 3209, South Africa.

Received: 29 July 2019 Accepted: 21 January 2020

Published online: 29 January 2020

\section{References}

1. Dachew BA, Azale Bisetegn T, Berhe Gebremariam R. Prevalence of mental distress and associated factors among undergraduate students of University of Gondar, Northwest Ethiopia: a cross-sectional institutional based study. PLoS One. 2015;10(3):e0119464.

2. Tariku GH, Zerihun AA, Bisrat ZS, Adissu GG, Jini D. Mental distress and its associated factors among students of Mizan Aman health science college, Ethiopia. J Med Sci. 2017;17(2):61-7.

3. James BO, Thomas IF, Omoaregba JO, Okogbenin EO, Okonoda KM, Ibrahim AW, Salihu AS, Oshodi YO, Orovwigho A, Odinka PC, et al. Psychosocial correlates of perceived stress among undergraduate medical students in Nigeria. Int J Med Educ. 2017:8:382-8.

4. Stallman HM. Psychological distress in university students: a comparison with general population data. Aust Psychol. 2010;45(4):249-57.

5. Soh N, Norgren S, Lampe L, Hunt G, Malhi G, Walter G. Mental distress in Australian medical students and its association with housing and travel time. J Contemp Med Educ. 2013;1(3):163-9.

6. Hakami R. Prevalence of psychological distress among undergraduate students at Jazan University: A cross-sectional study. Saudi J Med Med Sci. 2018;6(2):82-8

7. Sherina M, Rampal L, Kaneson N. Psychological stress among undergraduate medical students. Med J Malays. 2004;59(2):207-11.

8. Hersi L, Tesfay K, Gesesew H, Krahl W, Ereg D, Tesfaye M. Mental distress and associated factors among undergraduate students at the University of Hargeisa, Somaliland: a cross-sectional study. Int J Ment Health Syst. 2017;11: 39.

9. Melese B, Bayu B, Wondwossen F, Tilahun K, Lema S, Ayehu M, Loha E. Prevalence of mental distress and associated factors among Hawassa University medical students, southern Ethiopia: a cross-sectional study. BMC Res Notes. 2016;9(1):485.

10. Sreeramareddy CT, Shankar PR, Binu VS, Mukhopadhyay C, Ray B, Menezes RG. Psychological morbidity, sources of stress and coping strategies among undergraduate medical students of Nepal. BMC Med Educ. 2007;7:26.

11. Sani M, Mahfouz M, Bani I, Alsomily A, Alagi D, Alsomily N, Madkhaly F, Madkhali R, Hakami A, Hakami A. Prevalence of stress among medical students in Jizan University, Kingdom of Saudi Arabia. Gulf Med J. 2012;1(1): 19-25.

12. Onditi HZ, Moses I, Masatu FB. Psychosocial stressors and help-seeking behavior among undergraduate student teachers in Tanzania. Int J Learn Dev. 2014;4(1):98-114

13. Power JJ. Mental illness or mental distress; stigma and concealment in University students - a discussion paper. Int J Healthcare. 2016;2(1):29-37.

14. Tran A, Tran L, Geghre N, Darmon D, Rampal M, Brandone D, Gozzo JM, Haas H, Rebouillat-Savy K, Caci H, et al. Health assessment of French university students and risk factors associated with mental health disorders. PLoS One. 2017;12(11):e0188187.

15. Ambikile JS, Iseselo MK. Mental health care and delivery system at Temeke hospital in Dar Es Salaam, Tanzania. BMC Psychiatry. 2017;17(1):109.

16. WHO: A user's guide to the self reporting questionnaire (SRQ). Geneva: World Health Organization; 1994.

17. Nakimuli-Mpungu E, Mojtabai R, Alexandre PK, Katabira E, Musisi S, Nachega JB, Bass JK. Cross-cultural adaptation and validation of the self-reporting questionnaire among HIV+ individuals in a rural ART program in southern Uganda. HIV/AIDS (Auckland, NZ). 2012:4:51.

18. Frøland HTW, Sollesnes SG. Common Mental Disorders in rural Tanzania: How do patients explain their distress? Norway: The University of Bergen; 2010

19. Chipimo PJ, Fylkesnes K. Comparative validity of screening instruments for mental distress in Zambia. Clin Pract Epidemiol Ment Health. 2010;6:4.

20. Netsereab TB, Kifle MM, Tesfagiorgis RB, Habteab SG, Weldeabzgi YK, Tesfamariam OZ. Validation of the WHO self-reporting questionnaire-20 (SRQ-20) item in primary health care settings in Eritrea. Int J Ment Heal Syst. 2018;12(1):61.

21. van der Westhuizen C, Wyatt G, Williams JK, Stein DJ, Sorsdahl K. Validation of the self reporting questionnaire 20-item (SRQ-20) for use in a low-and middle-income country emergency Centre setting. Int J Ment Heal Addict. 2016:14(1):37-48

22. Zimet GD, Dahlem NW, Zimet SG, Farley GK. The multidimensional scale of perceived social support. J Pers Assess. 1988:52(1):30-41.

23. Farrer LM, Gulliver A, Bennett K, Fassnacht DB, Griffiths KM. Demographic and psychosocial predictors of major depression and generalised anxiety disorder in Australian university students. BMC Psychiatry. 2016;16:241.

24. Ndosi N, Waziri M. The nature of parasuicide in Dar Es Salaam, Tanzania. Soc Sci Med. 1997:44(1):55-61.

25. Bayati A, Beigi M, Salehi M. Depression prevalence and related factors in Iranian students. Pak J Biol Sci. 2009:12(20):1371-5.

\section{Publisher's Note}

Springer Nature remains neutral with regard to jurisdictional claims in published maps and institutional affiliations. 